Check for updates

Cite this: RSC Adv., 2018, 8, 15703

\title{
Synthesis of manganese-based complex as cathode material for aqueous rechargeable batteries $\uparrow$
}

\author{
Nan Qiu, (D) * Hong Chen, Zhaoming Yang, Sen Sun and Yuan Wang* \\ A low-cost and eco-friendly system based on a manganese-based complex cathode and zinc anode was \\ demonstrated. The cathode is able to reversibly (de-)insert $\mathrm{Zn}^{2+}$ ions, providing a high capacity of \\ $248 \mathrm{~mA} \mathrm{~h} \mathrm{~g}^{-1}$ at $0.1 \mathrm{~A} \mathrm{~g}^{-1}$. Ex situ TEM and XRD were utilized to determine the electrochemical \\ mechanism of this high capacity cathode. Moreover, the contribution of pre-added $\mathrm{Mn}^{2+}$ in electrolyte \\ to the capacity was revealed, and nearly $18.9 \%$ of the capacity is ascribed to the contribution of pre- \\ added $\mathrm{Mn}^{2+}$. With the help of additive, this aqueous rechargeable battery shows outstanding \\ electrochemical property. Its cycling performance is good with $6 \%$ capacity loss after 2000 cycles at \\ $4.0 \mathrm{~A} \mathrm{~g}^{-1}$, highlighting it as a promising system for aqueous rechargeable battery applications.
}

Received 6th March 2018

Accepted 23rd April 2018

DOI: $10.1039 / \mathrm{c} 8 \mathrm{ra01982g}$

rsc.li/rsc-advances

stability.$^{14}$ Nevertheless, the use of Co raise the cost and causes

\section{Introduction}

Due to the ever-increasing environmental concerns and energy demands, eco-friendly and renewable energy technologies have attracted much attention. ${ }^{1}$ With the development of sustainable and clean energy sources such as tides, wind and solar, stable and efficient stationary energy storage systems (ESSs) are crucial for the utilization of those renewable energy sources. ${ }^{2}$ Among various alternatives, lithium-ion batteries (LIBs) have be considered as a leading candidate for mobile and digital devices. ${ }^{3}$ Although LIBs achieve high energy density, ${ }^{4}$ some intrinsic properties of LIBs hinder their large-scale applications in stationary ESSs, where the safety, cost and durability are the primary factors. ${ }^{4}$ Therefore, safe, low-cost and stable aqueous rechargeable batteries (ARBs) are the promising alternatives for large-scale stationary ESSs.

To date, a number of ARBs have been inspected, such as monovalent ions batteries, ${ }^{5,6}$ divalent ions batteries, ${ }^{7,8}$ trivalent aluminium-ion batteries and mixed-ion batteries., ${ }^{9,10}$ Development of aqueous zinc-ion batteries are particularly attractive and have attracted much interest., ${ }^{4,11-13}$ Recently, cation-defect enhanced $\mathrm{ZnMn}_{2} \mathrm{O}_{4}$ spinel has been demonstrated as a cathode material. ${ }^{13}$ Unfortunately, inferior capacity make this cathode less feasible for large-scale stationary ESSs. Additionally, cobalt oxide have been exploited as cathodes, which shows high reversible capacity, good rate performance and high

Key Laboratory of Radiation Physics and Technology, Ministry of Education, Institute of Nuclear Science and Technology, Sichuan University, Chengdu 610064, People's Republic of China.E-mail: qiun@scu.edu.cn; wyuan@scu.edu.cn

$\dagger$ Electronic supplementary information (ESI) available: SEM images of cathode electrode in the charged/discharged state. Electrochemical performance of manganese-based complex in $1 \mathrm{M} \mathrm{ZnSO}_{4}$. Summary of electrochemical performance of different cathode materials for aqueous rechargeable batteries. See DOI: $10.1039 / \mathrm{c} 8 \mathrm{ra} 01982 \mathrm{~g}$ significant environmental concerns. ${ }^{15}$ On the other hand, manganese-based materials are relatively inexpensive because of the high abundance of manganese in the Earth's crust. ${ }^{16}$ Although manganese-based materials show some promise as cathodes for large-scale stationary ESSs, but the cathodes suffer poor rate-performance and significant capacity fading. ${ }^{17,18}$

In this work, we report an aqueous rechargeable battery based on $\mathrm{Zn}$ foil and low-cost manganese-based complex with high reversible capacity and long-cycle stability. The low energy consumption cathode exhibits an average discharge voltage of $1.32 \mathrm{~V}$ at $0.1 \mathrm{~A} \mathrm{~g}^{-1}$ and can be cycled at $100 \%$ coulombic efficiency at both low $\left(0.1 \mathrm{~A} \mathrm{~g}^{-1}\right)$ and high $\left(4.0 \mathrm{~A} \mathrm{~g}^{-1}\right)$ current density.

\section{Experimental}

\subsection{Material synthesis}

All chemical reagents were purchased from Aladdin Reagent Company (Shanghai, China) and used without any further purification. The synthetic procedure was conducted as follows: first, $2.535 \mathrm{~g}$ of $\mathrm{MnSO}_{4} \cdot \mathrm{H}_{2} \mathrm{O}$ and $3.422 \mathrm{~g}$ of $\left(\mathrm{NH}_{4}\right)_{2} \mathrm{~S}_{2} \mathrm{O}_{8}$ was dissolved in $100 \mathrm{ml}$ of deionized water (denoted as solution A). $2.16 \mathrm{~g}$ of $\mathrm{NaOH}$ was dissolved in $100 \mathrm{ml}$ of deionized water (denoted as solution B). Then, solution B was dropwise added to solution A under vigorous stirring. The mixed solution was kept stirring for 1 hour and aged overnight at room temperature. The precipitate was collected by filtration, washed with water and ethanol, and subsequently dried at $50{ }^{\circ} \mathrm{C}$.

\subsection{Characterizations}

X-ray diffraction (XRD) patterns of the samples were recorded on an Empyrean X-ray diffractometer using filtered $\mathrm{Cu} \mathrm{K \alpha}$ radiation at $40 \mathrm{kV}$ and $40 \mathrm{~mA}$. The morphologies of the samples 
were characterized by SEM using a field emission scanning electron microscope (FE-SEM, JEOL, JSM-7500F). Transmission electron microscope (TEM) images were obtained using a ZEISS LIBRA-200FE field emission transmission electron microscope operating at $200 \mathrm{kV}$. X-ray photoelectron spectroscopy (XPS) experiments were performed in a Kratos XSAM 800 instrument.

\subsection{Electrochemical measurements}

The electrochemical tests were carried out in coin-type cells (CR2032). The working electrodes were prepared as follows: the as-prepared material was mixed with carbon black (Super P) and polymer binder (polytetrafluoroethylene, PTFE) in a weight ratio of $70: 20: 10$ with the help of ethanol. After drying, the mixture was pressed into a film and cut into disk (diameter $10 \mathrm{~mm}$, thickness $\sim 90 \mu \mathrm{m}$, see Fig. S1 in ESI $\dagger$ ). The mass of cathode was measured by an electronic balance (Sartorius BSA124S, $0.1 \mathrm{mg}$ resolution). Several cathode were weighed and then used. The manganese-based complex mass loading is $2-3 \mathrm{mg} \mathrm{cm}^{-2}$. The coin cells were assembled in open air atmosphere using a manganese-based complex electrode as the cathode, a glass fibre (GF/D, Whatman) as the separator and a zinc foil (Alfa Aesar) as the anode. $0.2 \mathrm{ml}$ of $1 \mathrm{M} \mathrm{ZnSO}_{4}$ with $0.1 \mathrm{M} \mathrm{MnSO}_{4}$ as an additive in $\mathrm{H}_{2} \mathrm{O}$ was used as the electrolyte without oxygen removal. ${ }^{19}$ The charge-discharge (1.0-1.85 V vs. $\left.\mathrm{Zn} / \mathrm{Zn}^{2+}\right)$ tests were conducted on a LANHE battery tester (Wuhan, China) at room temperature. The cells were cycled at various current densities. A two-step charge process is employed. That is, the constant current charge step is followed by an additional constant voltage charge step till the current drops to two fifths of its initial value. The cyclic voltammetry (CV) tests were carried out using a CorrTest (CS150) electrochemical work station.

\section{Results and discussion}

The phase purity and crystal structure of the synthesized products were examined by using XRD. As shown in Fig. 1, the mainly peaks in the XRD patterns of as-prepared are identified using the standard $\mathrm{MnOOH}$ database (JCPDS no. 18-0804). ${ }^{20}$ The peaks are observed at $36.6^{\circ}$ and $65.3^{\circ}(2 \theta)$ could be indexed in partially crystalline $\mathrm{MnO}_{2}$ (JCPDS no. 42-1169). ${ }^{21,22}$ The morphology of as-prepared sample was confirmed by using a field emission scanning electron microscope (FE-SEM). As

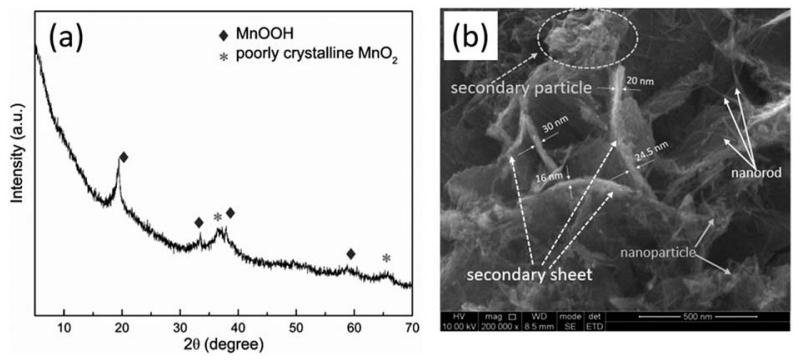

Fig. 1 Structural and morphological characterization of as-prepared sample. (a) XRD pattern and (b) SEM image of the as-prepared manganese-based complex. shown in Fig. 1b, the as-prepared particles consist of nanoparticle and nanorod, which agglomerated to each other, forming secondary particles with the size of a few hundred nanometers, and secondary sheets of about 16-30 nm in thickness.

The electrochemical properties of facile synthesized manganese-based complex ( $\mathrm{MnOOH}$ and $\mathrm{MnO}_{2}$ ) in aqueous rechargeable ion batteries was examined using coin-type (CR2032) cells. Based on the previous result, $\mathrm{MnSO}_{4}$ was used as additive to improve the cycling performance of manganesebased electrodes. ${ }^{7}$

In addition to the rate capability test, the cells were cycled at various charge/discharge current rates ranging from 0.1 to $4.0 \mathrm{~A} \mathrm{~g}^{-1}$ (based on the mass of manganese-based complex) over a potential window of $1.0-1.85 \mathrm{~V} v s$. $\mathrm{Zn} / \mathrm{Zn}^{2+}$. The manganesebased complex electrode shows an excellent rate capability (see Fig. 2a), delivering high specific charge and discharge capacities of $248,231,196,175,160,149$ and $131 \mathrm{~mA} \mathrm{~h} \mathrm{~g}^{-1}$ at $0.1,0.2,0.5,1.0,1.5,2.0$ and $4.0 \mathrm{~A} \mathrm{~g}^{-1}$, respectively.

The charge and discharge curves are shown in Fig. 2b. A constant voltage charge step was added till the charge current dropped to two fifths of its initial value. A small fraction (less than $2.4 \%$ ) of the total charge capacity was corresponding to the constant voltage step. Interestingly, with the increase in current density, the capacity drops in the first voltage plateau (denoted as region I, see Fig. 2b) are small, whereas capacity in the second voltage plateau (denoted as region II, see Fig. 2b) dramatically dropped, demonstrating that the reaction kinetics in the high plateau is extremely faster than the reaction in the low plateau. ${ }^{23}$ This is consistent with the results of CV analysis (see below). The average discharge voltage of this low-cost and safe ARB is about $1.32 \mathrm{~V}$. The cathode delivers an average specific energy density of $335 \mathrm{Wh} \mathrm{kg}^{-1}$ at $0.1 \mathrm{~A} \mathrm{~g}^{-1}$. Even at high current density, the cathode still exhibits a superior energy density (Table S1, see ESI $\dagger$ ). For example, the energy density is $198 \mathrm{Wh} \mathrm{kg}^{-1}$ at $2.0 \mathrm{~A} \mathrm{~g}^{-1}$. This is much higher than the values reported for aqueous $\mathrm{Zn}$-ion batteries, ${ }^{24-30}$ as well as aqueous $\mathrm{Li}$ ion batteries, ${ }^{\mathbf{6}, 31}$ or aqueous Na-ion batteries (Tables S1 and S2, see ESI $\dagger)^{32,33}$

For the evaluation of long-cycle stability, the cycling performance of manganese-based complex at $0.5,2.0$ and $4.0 \mathrm{Ag}^{-1}$ are shown in Fig. 2c. The manganese-based complex exhibited excellent cycling stability during repeated charge/discharge cycles. For the continuous cycling test, considerable capacity of $211 \mathrm{~mA} \mathrm{~h} \mathrm{~g}^{-1}$ is attained at $0.5 \mathrm{~A} \mathrm{~g}^{-1}$ after 50 cycles. The capacity retention for the manganese-based complex at $2.0 \mathrm{~A} \mathrm{~g}^{-1}$ is nearly $100 \%$ after 500 cycles, and high capacity of $150 \mathrm{~mA} \mathrm{~h} \mathrm{~g}^{-1}$ is obtained with high coulombic efficiency $(\sim 100 \%)$. For the higher current density test, it delivers a reversible capacity of $124 \mathrm{~mA} \mathrm{~h} \mathrm{~g}^{-1}$ at $4.0 \mathrm{~A} \mathrm{~g}^{-1}$ after 2000 cycles, corresponding to $93.9 \%$ of its initial capacity.

As shown in Fig. 3, ex situ XRD and TEM were used to understand the electrochemical mechanism of cathode. XRD pattern of charged electrode can be indexed to a cubic unit cell of the poorly crystalline $\mathrm{MnO}_{2}$ (JCPDS: 42-1169). ${ }^{21,22}$ For the discharged state, XRD pattern can be indexed to $\mathrm{MnOOH}$ (JCPDS: 74-1049) ${ }^{7}$ and $\mathrm{Zn}_{x} \mathrm{MnO}_{2} \cdot \mathrm{H}_{2} \mathrm{O}$ (JCPDS: 47-1825). ${ }^{34} \mathrm{HR}-$ 
TEM results (Fig. 3b and c) of discharged electrode confirmed the formation of $\mathrm{MnOOH}$ and $\mathrm{Zn}_{x} \mathrm{MnO}_{2} \cdot \mathrm{H}_{2} \mathrm{O}$. In the previous literature, the formation of $\mathrm{MnOOH}$ is attributed to the $\mathrm{H}^{+}$ insertion/extraction during discharge/charge processes. ${ }^{23}$ However, the concentration of $\mathrm{H}^{+}$ions in the electrolyte $(\mathrm{pH}=$ 4.3) is very low, and it may not the reason for the excellent electrochemical performance. Besides, $\mathrm{MnO}_{2}$ electrode shows good stability in the neutral electrolyte. ${ }^{35}$ To reduce the effect of
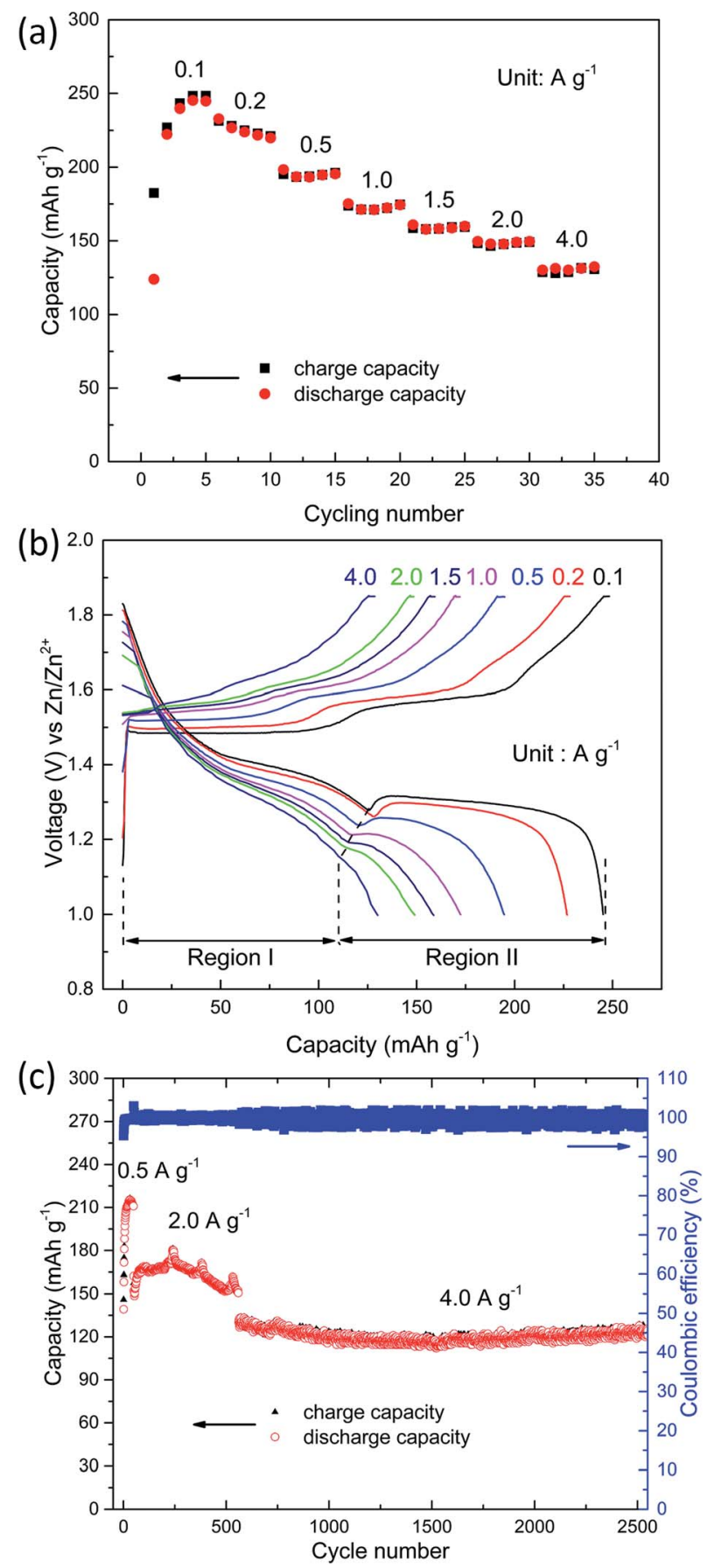

Fig. 2 Electrochemical performance of manganese-based complex. (a) Cycling performance at various current densities $\left(0.1-4.0 \mathrm{~A} \mathrm{~g}^{-1}\right)$. (b) Charge and discharge voltage profiles at various current densities between 1.0-1.85 V vs. Zn/Zn ${ }^{2+}$. (c) Long-term cycling performance of manganese-based complex.

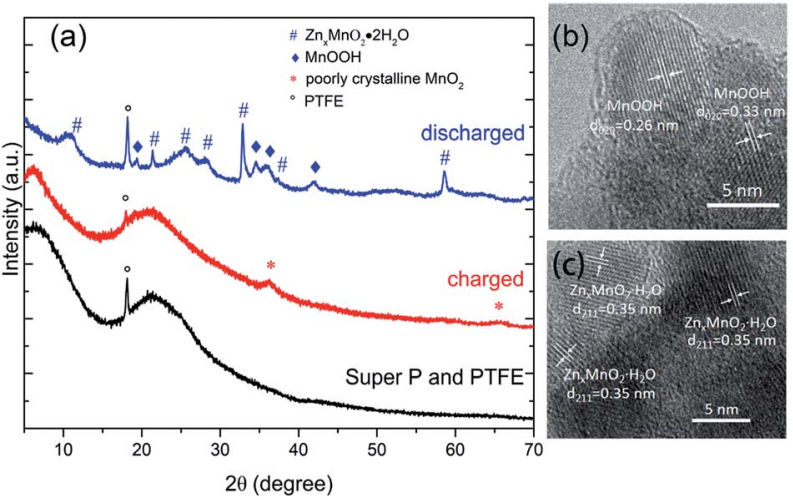

Fig. 3 Electrochemical mechanism studies on manganese-based complex during charge and discharge process. (a) XRD patterns of binder and conductive agent, manganese-based complex electrodes in charged and discharged states. ( $b$ and $c$ ) HRTEM images of manganese-based complex electrodes discharged to $1 \mathrm{~V}$.

$\mathrm{H}^{+}$ions, the $\mathrm{pH}$ value of the electrolyte was adjusted to 6.0 by adding ammonia. As shown in the Fig. 4, charge and discharge voltage profiles also show two plateaus in nearly neutral electrolyte. The results suggest that two plateaus may arise from the different sites in the $\mathrm{MnO}_{2}$. Moreover, hydrated zinc ion react with $\mathrm{MnO}_{2}$, and the accompanied water may provide $\mathrm{OH}^{-}$, which can produce $\mathrm{MnOOH}$.

The analysis of the oxidation states of the electrodes in charged and discharged states were carried out by XPS. As shown in the Fig. 5, Mn(III) and Mn(IV) are the dominant in the discharged and charged state, respectively. It suggested that the capacity of this manganese-based complex is ascribed to the reversible reaction of $\mathrm{Mn}(\mathrm{IV}) / \mathrm{Mn}$ (III).

Although the room-temperature synthesized manganesebased complex cathode with pre-addition of $\mathrm{Mn}^{2+}$ in electrolyte has been demonstrated excellent electrochemical performance, the underneath mechanism remains incompletely understood.

To further understand the function of $\mathrm{Mn}^{2+}$ electrolyte additive and the kinetics of the manganese-based complex electrode in this $\mathrm{ARB}, \mathrm{CV}$ measurements were performed at various scan rates from 0.1 to $1.0 \mathrm{mV} \mathrm{s}^{-1}$. As shown in Fig. 6a, two separated reversible redox peaks can be clearly identified in the first cycle at $0.1 \mathrm{mV} \mathrm{s}^{-1}$. The position of redox peaks was
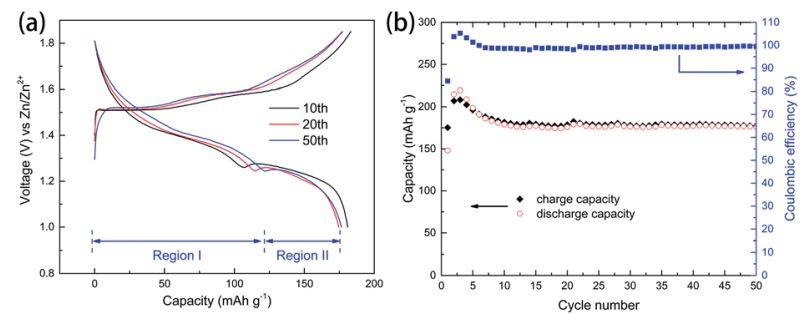

Fig. 4 Electrochemical performance of manganese-based complex in the ammonia-adjusted electrolyte $(\mathrm{pH}=6.0)$. (a) Charge and discharge voltage profiles at current density of $0.1 \mathrm{~A} \mathrm{~g}^{-1}$ in nearly neutral electrolyte (b) Cycling performance of manganese-based complex in nearly neutral electrolyte. 


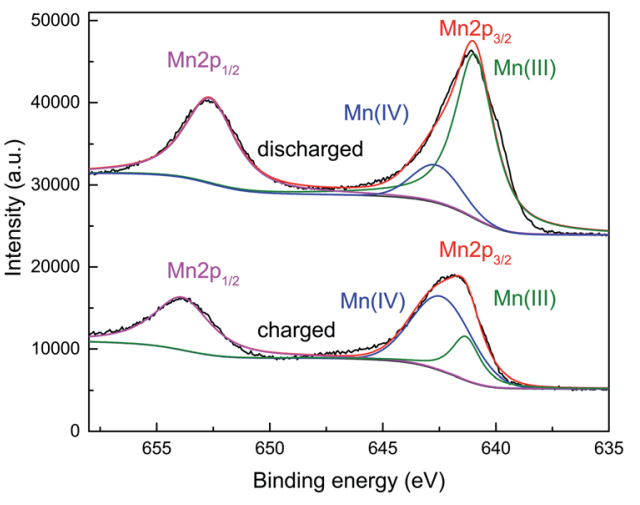

Fig. 5 XPS spectra of the manganese-based complex electrodes in charged and discharged states.

slightly affected by the additive. Whereas, the current density was obviously increased, which indicated the pre-added $\mathrm{Mn}^{2+}$ ions play an important role in the subsequent charge/discharge processes. For both cells, there are two pairs reduction/ oxidation peaks located at 1.25/1.53 and 1.39/1.60 $\mathrm{V}$ after the initial cycle (Fig. 6b), which implies pre-added $\mathrm{Mn}^{2+}$ ions did not affect the reaction mechanism for the manganese-based complex cathode in this $\mathrm{ARB}$, but provide additional capacity (Fig. S3 in ESI $\dagger$ ).

Two pairs reduction/oxidation peaks are in accordance with plateaus of the discharge/charge curves, corresponding to a two-step reaction. Besides, the CVs of manganese-based complex cathode remain invariable after several initial cycles, demonstrating the good reversibility. As presented in Fig. 6c-f, with the increase in CV scanning rate, the relative intensity $I_{1.25} \mathrm{~V} / I_{1.39} \mathrm{v}$ gradually decay, where $I_{1.25} \mathrm{~V}$ and $I_{1.39 \mathrm{~V}}$ is intensity of peak located around $1.25 \mathrm{~V}$ and $1.39 \mathrm{~V}$, respectively. The results suggest that, as the current increases, the capacity fading rate at the upper voltage plateau (corresponding to region I) is slower than that at the lower voltage plateau (corresponding to region II), which is consistent with the results of the charge/discharge experiments. It also means that the kinetics of manganese-based complex electrodes is not influenced by pre-addition of $\mathrm{Mn}^{2+}$ in electrolyte.

As for the long-cycle stability induced by the pre-addition of $\mathrm{Mn}^{2+}$, the cells were experienced low rate tests $(5$ cycles at $0.1 \mathrm{~A} \mathrm{~g}^{-1}$ ), subsequently long-term cyclic test (2000 cycles at $4.0 \mathrm{~A} \mathrm{~g}^{-1}$ ), and finally recovered at $0.1 \mathrm{~A} \mathrm{~g}^{-1}$. The results can be seen in Fig. 7, which clearly show that capacity of the region II was enhanced by the pre-addition of $\mathrm{Mn}^{2+}$ in electrolyte. The dissolution-inhibiting effect of $\mathrm{Mn}^{2+}$ form the manganesebased cathode may explain why the cell with $\mathrm{MnSO}_{4}$ additive shows high specific capacity. But why is $\mathrm{Zn}^{2+}$ insertion in the region II only severely affected, which is still unknown, unless the mechanisms involved in system are fully understood.

To probe the contribution of the extra capacity caused by $\mathrm{Mn}^{2+}$ electrolyte additive in this $\mathrm{ARB}$, coin cells using different cathode electrodes were assembled. Homemade carbon current collector (Super P : PTFE $=9: 1$ ) and stainless foil served as cathode electrode, respectively. As shown in

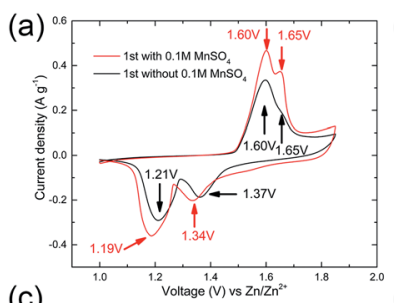

(c)

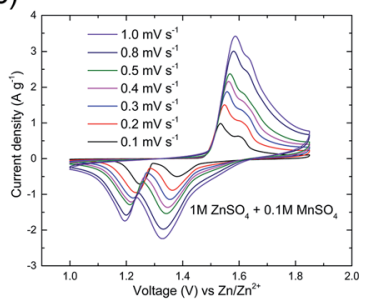

(d)
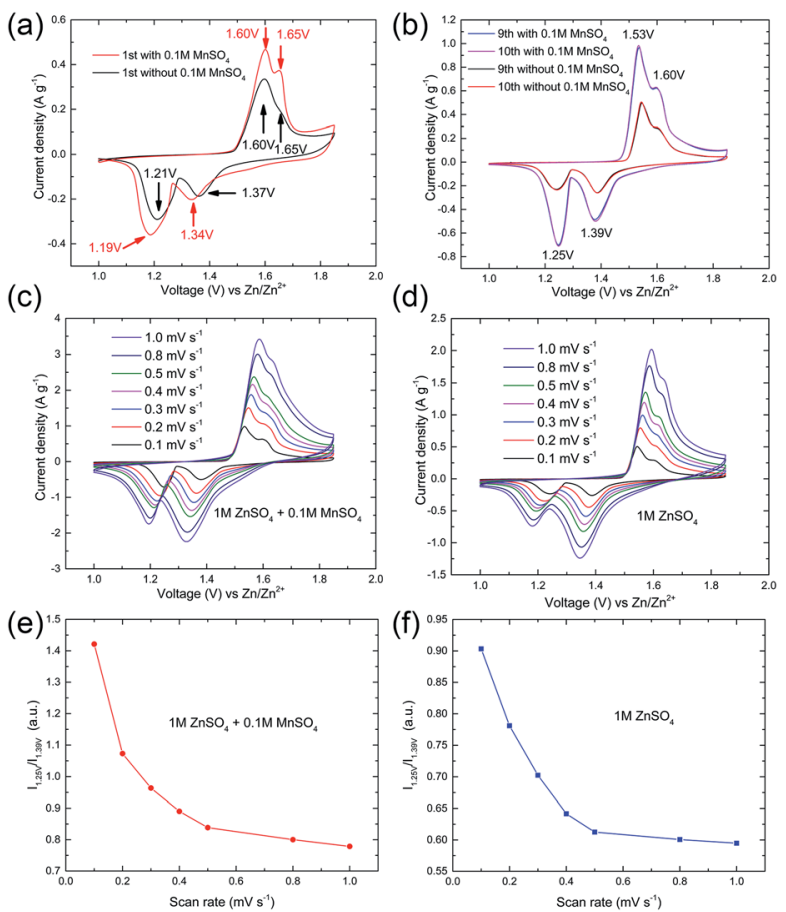

Fig. 6 ( $a$ and b) CV curves of manganese-based complex electrode with/without $0.1 \mathrm{M} \mathrm{MnSO} 4$ scanning at $0.1 \mathrm{mV} \mathrm{s}^{-1}$. (c and d) CV curves of manganese-based complex electrode at different scan rates from 0.1 to $1 \mathrm{mV} \mathrm{s}^{-1}$. (e and f) The relative intensity $I_{1.25} \mathrm{v} / I_{1.39} \vee$ gradually decay, $I_{1.25} \mathrm{v}$ and $I_{1.39} \mathrm{v}$ is intensity of peak located around $1.25 \mathrm{~V}$ and $1.39 \mathrm{~V}$, respectively.

Fig. 8a, cell with conductive carbon delivered negligible capacity in the absence of $\mathrm{Mn}^{2+}$ in the electrolyte. However, the situation was different when the electrolyte containing $0.1 \mathrm{M} \mathrm{MnSO}_{4}$. The reversible capacity increased slowly every cycle in the initial stage, and continuously increased to 0.059 $\mathrm{mA} \mathrm{h}$, which is nearly $18.9 \%$ for the reversible capacity of the active material (see caption in Fig. 8). It is much higher than the one in the previous literature, ${ }^{19}$ and indicates that the contribution of pre-added $\mathrm{Mn}^{2+}$ in electrolyte to the cathode capacity cannot be neglected. Moreover, stable and less capacity can be obtained when the conductive carbon is substituted by stainless foil. The results suggest that the both conductive carbon and $\mathrm{Mn}^{2+}$ in the electrolyte are critical for the extra considerable capacity.
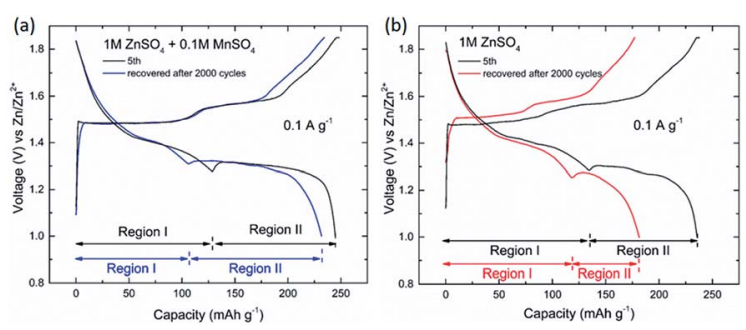

Fig. 7 Charge/discharge voltage profiles of manganese-based complex cathode in the initial stage (5th) and recovered stage (after 2000 cycles at $4.0 \mathrm{~A} \mathrm{~g}^{-1}$ ) at low current density. 

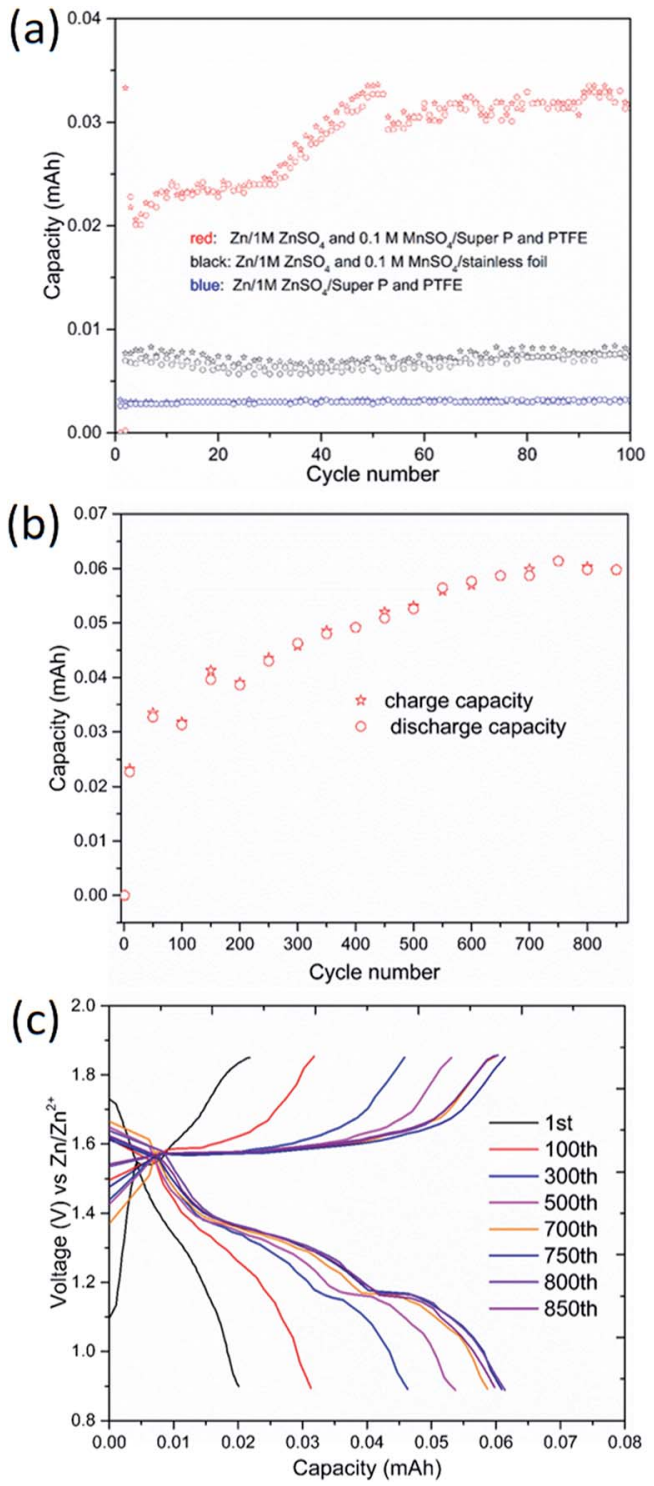

Fig. 8 The effect of $\mathrm{Mn}^{2+}$ in electrolyte in this ARB. (a) Charge/ discharge capacity of various cells at $2 \mathrm{~mA} \mathrm{~cm}^{-2}$ using $1 \mathrm{M} \mathrm{ZnSO}_{4}$ with/ without $0.1 \mathrm{M} \mathrm{MnSO}_{4}$. (b) Long-term cycling performance of $\mathrm{Zn} / 1 \mathrm{M}$ $\mathrm{ZnSO}_{4}+0.1 \mathrm{M} \mathrm{MnSO}_{4} /$ Super $\mathrm{P}$ cell. The $\mathrm{MnSO}_{4}$ additive-generated manganese oxide could deliver a capacity of $0.059 \mathrm{~mA} \mathrm{~h}$, which is nearly $18.9 \%$ for the reversible capacity $\left(1.89 \mathrm{mg} \times 165 \mathrm{~mA} \mathrm{~h} \mathrm{~g}{ }^{-1}=\right.$ $0.312 \mathrm{~mA} \mathrm{~h}$ ) of the active material. (c) Charge/discharge profiles of $\mathrm{Zn} /$ $1 \mathrm{M} \mathrm{ZnSO}_{4}+0.1 \mathrm{M} \mathrm{MnSO}_{4} /$ Super P cell.

\section{Conclusions}

In summary, an aqueous rechargeable battery based on manganese-based complex and zinc foil using mild $1 \mathrm{M} \mathrm{ZnSO}_{4}$ electrolyte with/without $0.1 \mathrm{M} \mathrm{MnSO}_{4}$ was demonstrated. This low-cost and eco-friendly cathode delivers a capacity of $248 \mathrm{~mA} \mathrm{~h} \mathrm{~g}^{-1}$, an energy density of $335 \mathrm{Wh} \mathrm{kg}^{-1}$ at $0.1 \mathrm{~A} \mathrm{~g}^{-1}$. It shows a capacity retention of $100 \%, 93.9 \%$ over 500,2000 cycles at $2.0,4.0 \mathrm{~A} \mathrm{~g}^{-1}$, respectively. Poorly crystalline $\mathrm{MnO}_{2}$ is formed in the charged state, and it is able to reversibly insert $\mathrm{Zn}^{2+}$ ions. The effect of $\mathrm{Mn}^{2+}$ in electrolyte in this ARB also has been investigated. Nearly $18.9 \%$ of the capacity is ascribed to the contribution of pre-added $\mathrm{Mn}^{2+}$. This study could lead to a promising safe, low-cost and highly stable battery system for application in large-scale storage.

\section{Conflicts of interest}

There are no conflicts to declare.

\section{Acknowledgements}

This work was financially supported by start-up funding provided by Sichuan University (2017SCU11066). This research was also partially supported by National Natural Science Foundation of China (Grant No. 11505121 and 11775150), International Science and Technology Cooperation Program of China (2014DFR50710). We also appreciate the supports from Key Laboratory of Nuclear Materials and Safety Assessment (2017NMSAKF02).

\section{References}

1 D. Larcher and J. M. Tarascon, Nat. Chem., 2015, 7, 19-29.

2 J. F. Parker, C. N. Chervin, I. R. Pala, M. Machler, M. F. Burz, J. W. Long and D. R. Rolison, Science, 2017, 356, 415-418.

3 E. McCalla, A. M. Abakumov, M. Saubanère, D. Foix, E. J. Berg, G. Rousse, M.-L. Doublet, D. Gonbeau, P. Novák, G. Van Tendeloo, R. Dominko and J.-M. Tarascon, Science, 2015, 350, 1516-1521.

4 M. C. Lin, M. Gong, B. Lu, Y. Wu, D. Y. Wang, M. Guan, M. Angell, C. Chen, J. Yang, B. J. Hwang and H. Dai, Nature, 2015, 520, 325-328.

5 H. Kim, J. Hong, K.-Y. Park, H. Kim, S.-W. Kim and K. Kang, Chem. Rev., 2014, 114, 11788-11827.

6 L. Suo, O. Borodin, T. Gao, M. Olguin, J. Ho, X. Fan, C. Luo, C. Wang and K. Xu, Science, 2015, 350, 938-943.

7 H. L. Pan, Y. Y. Shao, P. F. Yan, Y. W. Cheng, K. S. Han, Z. M. Nie, C. M. Wang, J. H. Yang, X. L. Li, P. Bhattacharya, K. T. Mueller and J. Liu, Nat. Energy, 2016, 1, 16039.

8 J. Y. Luo and Y. Y. Xia, Adv. Funct. Mater., 2007, 17, 38773884.

9 B. Zhang, Y. Liu, X. Wu, Y. Yang, Z. Chang, Z. Wen and Y. Wu, Chem. Commun., 2014, 50, 1209-1211.

10 V. Mathew, S. Kim, J. Kang, J. Gim, J. Song, J. P. Baboo, W. Park, D. Ahn, J. Han, L. Gu, Y. Wang, Y.-S. Hu, Y.-K. Sun and J. Kim, NPG Asia Mater., 2014, 6, e138.

11 X. Wu, Y. Qi, J. J. Hong, Z. Li, A. S. Hernandez and X. Ji, Angew. Chem., Int. Ed. Engl., 2017, 56, 13026-13030.

12 K. W. Nam, S. Kim, S. Lee, M. Salama, I. Shterenberg, Y. Gofer, J.-S. Kim, E. Yang, C. S. Park, J.-S. Kim, S.-S. Lee, W.-S. Chang, S.-G. Doo, Y. N. Jo, Y. Jung, D. Aurbach and J. W. Choi, Nano Lett., 2015, 15, 4071-4079.

13 S. Gheytani, Y. Liang, F. Wu, Y. Jing, H. Dong, K. K. Rao, X. Chi, F. Fang and Y. Yao, Adv. Sci., 2017, 4, 1700465.

14 C. Xu, Y. Chen, S. Shi, J. Li, F. Kang and D. Su, Sci. Rep., 2015, 5,14120 . 
15 D. Kundu, B. D. Adams, V. Duffort, S. H. Vajargah and L. F. Nazar, Nat. Energy, 2016, 1, 16119.

16 F. Wang, F. Yu, X. Wang, Z. Chang, L. Fu, Y. Zhu, Z. Wen, Y. Wu and W. Huang, ACS Appl. Mater. Interfaces, 2016, 8, 9022-9029.

17 L. Chen, Q. Gu, X. Zhou, S. Lee, Y. Xia and Z. Liu, Sci. Rep., 2013, 3, 1946.

18 P. He, M. Yan, G. Zhang, R. Sun, L. Chen, Q. An and L. Mai, Adv. Energy Mater., 2017, 7, 1601920.

19 N. Zhang, F. Cheng, J. Liu, L. Wang, X. Long, X. Liu, F. Li and J. Chen, Nat. Commun., 2017, 8, 405.

20 H. Chen, S. Zeng, M. Chen, Y. Zhang and Q. Li, RSC Adv., 2017, 7, 8561-8566.

21 J. Ni, W. Lu, L. Zhang, B. Yue, X. Shang and Y. Lv, J. Phys. Chem. C, 2009, 113, 54-60.

22 C. Xu, B. Li, H. Du and F. Kang, Angew. Chem., Int. Ed., 2012, 51, 933-935.

23 W. Sun, F. Wang, S. Hou, C. Yang, X. Fan, Z. Ma, T. Gao, F. Han, R. Hu, M. Zhu and C. Wang, J. Am. Chem. Soc., 2017, 139, 9775-9778.

24 N. Zhang, F. Cheng, Y. Liu, Q. Zhao, K. Lei, C. Chen, X. Liu and J. Chen, J. Am. Chem. Soc., 2016, 138, 12894-12901.
25 B. Lee, H. R. Lee, H. Kim, K. Y. Chung, B. W. Cho and S. H. Oh, Chem. Commun., 2015, 51, 9265-9268.

26 C. Xu, B. Li, H. Du and F. Kang, Angew. Chem., Int. Ed., 2012, 51, 933-935.

27 R. Trocoli and F. La Mantia, ChemSusChem, 2015, 8, 481-485.

28 L. Y. Zhang, L. Chen, X. F. Zhou and Z. P. Liu, Adv. Energy Mater., 2015, 5, 1400930.

29 M. H. Alfaruqi, J. Gim, S. Kim, J. Song, D. T. Pham, J. Jo, Z. Xiu, V. Mathew and J. Kim, Electrochem. Commun., 2015, 60, 121-125.

30 M. H. Alfaruqi, J. Gim, S. Kim, J. Song, J. Jo, S. Kim, V. Mathew and J. Kim, J. Power Sources, 2015, 288, 320-327.

31 W. Tang, Y. Hou, F. Wang, L. Liu, Y. Wu and K. Zhu, Nano Lett., 2013, 13, 2036-2040.

32 R. Qiao, K. Dai, J. Mao, T.-C. Weng, D. Sokaras, D. Nordlund, X. Song, V. S. Battaglia, Z. Hussain, G. Liu and W. Yang, Nano Energy, 2015, 16, 186-195.

33 W.-J. Li, S.-L. Chou, J.-Z. Wang, J.-L. Wang, Q.-F. Gu, H.-K. Liu and S.-X. Dou, Nano Energy, 2015, 13, 200-207.

34 N. Qiu, H. Chen, Z. Yang, S. Sun and Y. Wang, Electrochim. Acta, 2018, 272, 154-160.

35 Q. Qu, P. Zhang, B. Wang, Y. Chen, S. Tian, Y. Wu and R. Holze, J. Phys. Chem. C, 2009, 113, 14020-14027. 